\title{
Measurement of the cross linking compound, pyridinoline, in urine as an index of collagen degradation in joint disease
}

\author{
SIMON P ROBINS, ${ }^{1}$ PHYLLIS STEWART,${ }^{1}$ CAROL ASTBURY ${ }^{2}$ AND \\ HOW ARD A BIRD
}

From the ${ }^{1}$ Rowett Research Institute, Bucksburn, Aberdeen; and the ${ }^{2}$ Clinical Pharmacology Unit, Royal Bath Hospital, Harrogate

SUMmARY An enzyme linked immunoassay (ELISA) for the collagen cross link, pyridinoline, has been developed using affinity purified antibodies, with a sensitivity down to about $0 \cdot 1 \mathrm{ng}$ of cross link. Measurements of urinary pyridinoline were made in patients with rheumatoid arthritis (RA), osteoarthritis (OA), and a control group showing no signs of joint disease. Expressed relative to creatinine values, pyridinoline was significantly increased in both RA and OA groups compared with controls: these differences were much larger than could be attributed to any age related effects or to changes in urinary creatinine concentrations. These findings were confirmed by analysis of a series of $24 \mathrm{~h}$ urine collections which showed that the total pyridinoline excretions were significantly higher in both RA and OA groups than in the controls. As pyridinoline is much more prevalent in cartilage than in bone collagen, measurement of this compound in urine may provide an index for monitoring the increased joint destruction that occurs in arthritic disease.

Key words: immunoassay, pyridinium cross links of collagen, cartilage degradation.

Measurement of urinary hydroxyproline has been widely used as an index of collagen degradation ${ }^{1}$ and has found applications in monitoring disorders involving excessive collagen resorption. ${ }^{2} 3$ The usefulness of this technique is, however, limited by the poor sensitivity caused by metabolism of large amounts of hydroxyproline in the liver. Further complications arise from the release of hydroxyproline at several stages of collagen biosynthesis and maturation, including procollagen degradation ${ }^{4}$ and processing. ${ }^{5}$ Measurement of hydroxylysine glycosides was proposed as a more sensitive index, ${ }^{6}$ with the additional advantage that the relative amounts of mono- and disaccharide appeared to provide information on collagen degradation in different tissues. ${ }^{7}$ More recent evidence, particularly relating to the contribution made by the serum complement component, Clq, has cast doubt on the validity of this technique. ${ }^{8}$ Development of indices

Accepted for publication 21 May 1986.

Correspondence to Dr Simon P Robins, Biochemistry Division, The Rowett Research Institute, Greenburn Road, Bucksburn, Aberdeen AB2 9SB. for collagen degradation based on the release of cross linking components has potential advantages over previous methods both in specificity and sensitivity. In particular, measurement of cross links would indicate degradation of mature collagen fibrils rather than release from all intermediates formed during the extensive postribosomal processing of collagen.

Pyridinoline is a 3-hydroxypyridinium compound ${ }^{9}$ that is formed by interactions involving an intermediate bifunctional cross link ${ }^{1011}$ to give a stable amino acid derivative linking three collagen chains. ${ }^{12}$ The compound is most prevalent in cartilage, is a relatively minor cross linking constituent of bone, and is totally absent in normal dermal collagen. ${ }^{13}{ }^{14}$ Pyridinoline has been detected in normal human urine both immunochemically ${ }^{15}$ and by conventional chromatographic procedures. ${ }^{16} 17$

This paper gives the results of preliminary studies of urinary pyridinoline measurement in patients with either rheumatoid arthritis (RA) or osteoarthritis (OA) in comparison with control groups showing no sign of joint disease. 


\section{Patients and methods}

\section{PATIENTS}

Patients with osteoarthrosis were selected because of definite radiological evidence of osteoarthrosis of the knee or hip, or both, and the clinical absence of gout or rheumatoid disease. Patients with rheumatoid arthritis were selected because they complied with the American Rheumatism Association criteria (classical or definite disease) and had definite radiological changes. All patients were undergoing inpatient treatment for their arthritis at a regional rheumatology centre in Harrogate. Patients were receiving a variety of analgesics or anti-inflammatory agents, or both, and some of the rheumatoid patients were also receiving second line therapy. Urine specimens were provided by the patients with the assistance of the nursing staff. The specimens were collected at various times during the day in an attempt to randomise the possible effects of physiotherapy on urinary pyridinoline. Paired specimens were separated by an interval of three to five days. No attempt was made to keep drug therapy constant during this interval. For the major part of this study the control group comprised hospitalised patients showing no clinical or biochemical evidence of abnormal muscle metabolism or of joint disease. In a subsequent study, where $24 \mathrm{~h}$ urine collections were made, the controls were normal volunteers of similar ages to those of additional RA and OA groups selected according to the criteria described previously.

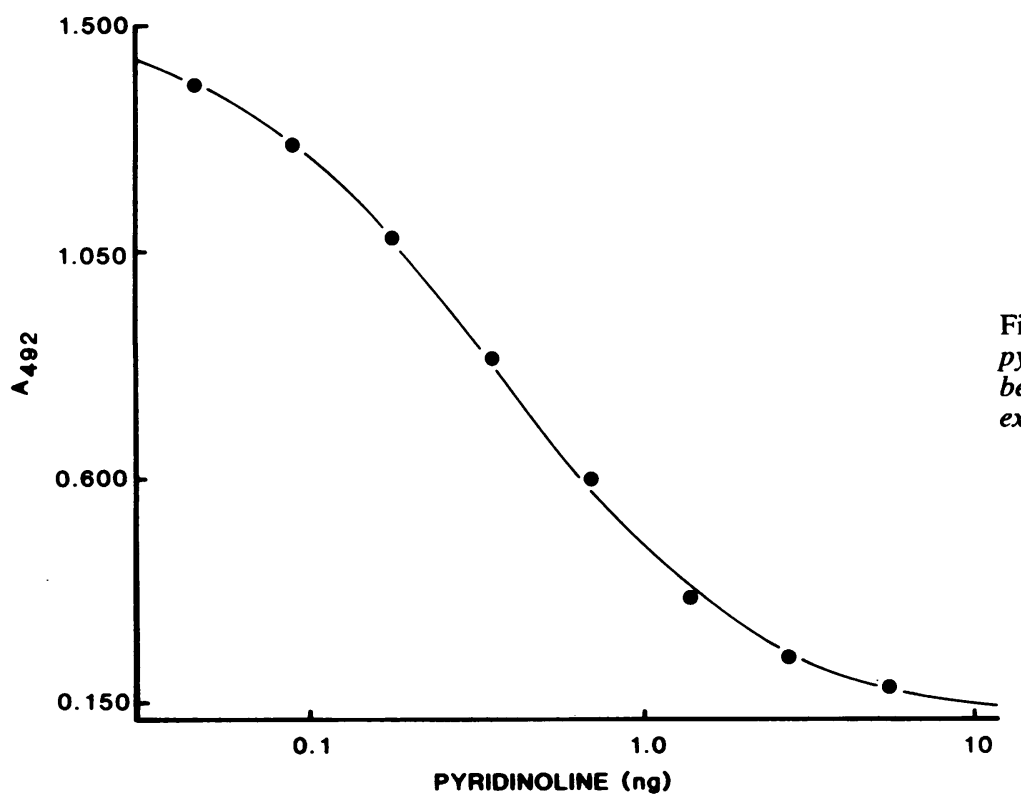

PREPARATION OF ANTIBODIES

Antisera to pyridinoline covalently linked to bovine $\frac{}{m}$ serum albumin were raised in rabbits as described previously. ${ }^{15}$ The antiserum was affinity purified $\stackrel{\vec{F}}{\stackrel{(}{\circ}}$ using a column prepared by covalent attachment ofo pyridinoline to Sepharose 4B (Pharmacia Ltd, 을 Milton Keynes, Bucks, UK) by reductive amination $\frac{}{\supset}$ of periodate oxidised beads. ${ }^{18}$ To overcome steric $\stackrel{\mathbb{D}^{\mathbb{D}}}{2}$ hindrance of antibody binding it was necessary@ initially to attach hydroxylysine as a spacer, whereupon further treatment with $0 \cdot 1 \mathrm{M}$ sodium periodate. generated aldehyde groups at the hydroxylysine side $\vec{\omega}$ chain for attachment of pyridinoline by reduction with sodium cyanoborohydride. ${ }^{15}$ The affinity purified antibodies were divided into small aliquots and stored at $-30^{\circ} \mathrm{C}$.

COMPETITIVE ELISA FOR PYRIDINOLINE

Microtitre plates (Dynatech Ltd, Lewes, Sussex, UK) were coated with $0.2 \mu \mathrm{g} /$ well of pyridinoline-응 gelatin. ${ }^{15}$ The sample or standard solutions dissolved in phosphate buffered saline containing $0.05 \%$ Tween 20 (PBS-Tween) were incubated at room temperature for two hours with an equal 3 volume $(0.1 \mathrm{ml})$ of pyridinoline antibody solution in the same buffer. After washing with PBS-Tween the plates were incubated for one hour with goat ${ }_{\infty}$ antirabbit IgG-peroxidase conjugate. After the. addition of $o$-phenylenediamine substrate in citrate? buffer containing $0.02 \% \mathrm{H}_{2} \mathrm{O}_{2}$ colour development was stopped after $15 \mathrm{~min}$ by the addition of $3 \mathrm{M} \overline{-}$ $\mathrm{H}_{2} \mathrm{SO}_{4}(0 \cdot 1 \mathrm{ml})$ and the absorbance at $492 \mathrm{~nm}\left(\mathrm{~A}_{492}\right) \stackrel{2}{\varrho}$

Fig. 1 Inhibition ELISA for pyridinoline. The curve represents the $\mathrm{O}$ best-fit logistic curve through the experimental points shown. 
Table 1 Urinary pyridinoline and creatinine values*

\begin{tabular}{|c|c|c|c|c|c|}
\hline Group & $\begin{array}{l}\text { No of } \\
\text { patients }\end{array}$ & $\begin{array}{l}\text { Mean age } \\
\text { (range) }\end{array}$ & $\begin{array}{l}\text { Pyridinoline } \\
\text { (nmolll) }\end{array}$ & $\begin{array}{l}\text { Creatinine } \\
(\mathrm{mg} / 100 \mathrm{ml}) \dagger\end{array}$ & $\begin{array}{l}\text { Pyd./Creat. } \\
\text { (nmol/mmol) }\end{array}$ \\
\hline Control & 10 & $\begin{array}{l}47 \\
(21-80)\end{array}$ & $49.9(21 \cdot 2)$ & $132.4(78.9)$ & $5.4(3.7)$ \\
\hline RA & 11 & $\begin{array}{l}63 \\
(42-75)\end{array}$ & $126 \cdot 6(50 \cdot 8)$ & $85 \cdot 1(32 \cdot 2)$ & $18 \cdot 9(9 \cdot 3) \ddagger$ \\
\hline OA & 20 & $\begin{array}{l}65 \\
(43-87)\end{array}$ & $85 \cdot 5(29 \cdot 6)$ & $73.7(40 \cdot 4)$ & $17 \cdot 7(9 \cdot 5) \ddagger$ \\
\hline
\end{tabular}

*Values are expressed as mean (SD).

†SI conversion: creatinine $\mathrm{mg} / 100 \mathrm{ml} \times 0.0884=\mathrm{mmol} / \mathrm{l}$.

$\ddagger$ Significantly higher than control group, $\mathrm{p}<0.001$.

was read with a Titertek Multiskan (Flow Laboratories Ltd, Irvine, Scotland, UK). Each sample was analysed in triplicate with duplicate pyridinoline standards run on each microtitre plate. Analysis of the standard data by logistic curve fitting together with interpolation for unknowns was achieved with a Maximum Likelihood Program ${ }^{19}$ run on a Prime 550 computer.

PREPARATION OF URINE SAMPLES

The collected urines were acidified to $\mathrm{pH} 2$ with $\mathrm{HCl}$ and stored at $-20^{\circ} \mathrm{C}$. Experiments have shown that pyridinoline in urine is completely stable under these conditions for at least one year (S P Robins, unpublished results).

After preliminary experiments to determine the conditions of hydrolysis necesssary for complete release of pyridinoline, urine samples $(1.0 \mathrm{ml})$ were hydrolysed in $3 \mathrm{M} \mathrm{HCl}$ at $107^{\circ} \mathrm{C}$ for 16 hours. After most of the $\mathrm{HCl}$ had been removed in a vacuum desiccator over solid $\mathrm{NaOH}$ the samples were redissolved in water, any insoluble material centrifuged down, and the supernatant again evaporated to dryness. The residues were dissolved in PBSTween and were diluted with the same buffer so that aliquots $(0 \cdot 1 \mathrm{ml})$ used for the assay corresponded to between 5 and $50 \mu$ lof urine.

STATISTICAL PROCEDURES

Analysis of differences between groups in pyridinoline/creatinine ratios employed the Mann-Whitney $\mathrm{U}$ test.

\section{Results}

As shown by a typical inhibition ELISA with standards (Fig. 1) the detection limit of the assay was approximately $0 \cdot 1 \mathrm{ng}$ of pyridinoline. Tests with hydroxylysine, desmosines, and related pyridinium and amino acid derivatives showed less than $0.25 \%$ cross reaction with the antibody. In addition, the slope of the line generated by analysis of serial dilutions of a hydrolysed urine sample was similar to that of the standard curve, indicating that the antibody affinity for the measured compound was the same as for pyridinoline.

Preliminary experiments using different concentrations of acid for hydrolysis showed that full release of pyridinoline from urine was achieved with $3 \mathrm{M} \mathrm{HCl}$, and these conditions were used for the present study. Some free cross link was detected without hydrolysis, but this did not represent a consistent proportion of that measured in the hydrolysates (see 'Discussion').

Details of the three patient groups used for the major study are given in Table 1 together with

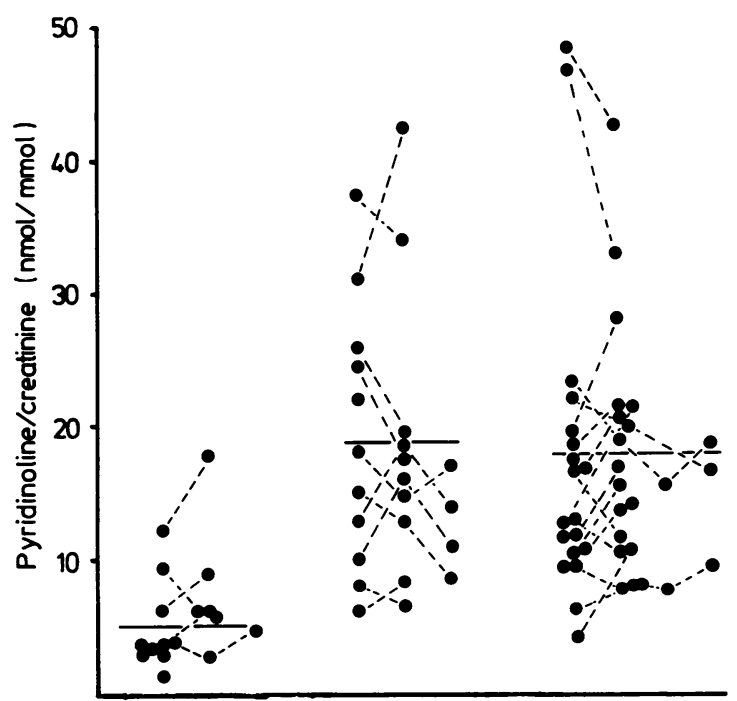

Control grap Rheumatoid arthritis Osteoarthritis

Fig. 2 Urinary pyridinoline/creatinine ratios in patients with $R A$ and $O A$ compared with a control group. The broken lines link repeat samples from individual patients taken at intervals of three to five days. Horizontal lines indicate mean values. 
Table 2 Pyridinoline in $24 h$ urine collections compared with values ${ }^{*}$ relative to creatinine excretion

\begin{tabular}{|c|c|c|c|c|c|}
\hline \multirow[t]{2}{*}{ Group $^{\dagger}$} & \multirow{2}{*}{$\begin{array}{l}\text { Mean age } \\
\text { (range) }\end{array}$} & \multicolumn{2}{|l|}{ Pyridinoline } & \multirow{2}{*}{$\begin{array}{l}\text { Creatinine\$ } \\
(\mathrm{mg} / 100 \mathrm{ml})\end{array}$} & \multirow{2}{*}{$\begin{array}{l}\text { Pyd./Creat. } \\
\text { (nmol/mmol) }\end{array}$} \\
\hline & & (nmol/l) & $(n m o l / 24 h)$ & & \\
\hline Control & $\begin{array}{l}53 \\
(50-56)\end{array}$ & $51 \cdot 5(15 \cdot 2)$ & $68 \cdot 5(27 \cdot 7)$ & $78.9(46 \cdot 1)$ & $6 \cdot 4(3 \cdot 3)$ \\
\hline RA & $\begin{array}{l}60 \\
(57-67)\end{array}$ & $269 \cdot 0(228 \cdot 9)$ & $302 \cdot 6(113 \cdot 2) \div$ & $76 \cdot 7 \cdot(41 \cdot 7)$ & $36 \cdot 5(9 \cdot 2)$ \\
\hline $\mathrm{OA}$ & $\begin{array}{l}70 \\
(55-77)\end{array}$ & $105 \cdot 4(28 \cdot 2)$ & $175 \cdot 7(46 \cdot 7) \ddagger$ & $49 \cdot 1(12 \cdot 2)$ & $25 \cdot 1(7 \cdot 1)$ \\
\hline
\end{tabular}

*Values are expressed as mean (SD).

tEach group comprised five individuals.

$\ddagger$ Significantly higher than the control group, $\mathrm{p}<0.01$.

\$SI conversion: creatinine $\mathrm{mg} / 100 \mathrm{ml} \times 0.0884=\mathrm{mmol} / \mathrm{l}$.

values for urinary pyridinoline and creatinine concentrations. The pyridinoline/creatinine ratios shown in Fig. 2 include, for certain individuals, the variations recorded for serial urine samples taken usually at one week intervals. For both the RA and OA groups the pyridinoline/creatinine ratios were significantly raised compared with that of the control group. Overall there was no correlation (coefficient $\mathrm{r}=0 \cdot 192, \mathrm{p}>0.05$ ) between pyridinoline and creatinine levels. Investigation of the possibility that the pyridinoline/creatinine ratio was affected by changes in the denominator showed that there was no significant difference in creatinine levels between the control and RA groups; the patients with OA, however, had lower creatinine levels than the controls $(p \simeq 0 \cdot 01)$, though this difference is unlikely to account fully for the observed increase in pyridinoline/creatinine ratio. A further study in which $24 \mathrm{~h}$ urine collections were analysed confirmed that the total urinary pyridinoline excretions were significantly higher in both the RA and OA groups than in the control group (Table 2). In this second series of experiments creatinine levels in the patients with OA were lower than in the other two groups, though these results were based on relatively small numbers of patients. The differences in total pyridinoline excretions between the RA and OA groups were not statistically significant.

\section{Discussion}

The results of this preliminary study show significantly increased amounts of pyridinoline in the urine of patients with arthritic disease. This conclusion was valid not only when the results were expressed relative to creatinine levels but also as total excretion of the cross link per day. Aberrations due to changes in creatinine levels can, therefore, be largely discounted, and, in particular, the lack of correlation between pyridinoline and creatinine precludes the possibility that kidney dysfunction contributed to the increased pyridinoline excretion. In general both patients with RA and OA showed similar increases in the pyridinoline/creatinine ratio, an index which appears therefore to reflect joint destruction, a process common to both types of disorder. In this context the major source of urinary pyridinoline is likely to be from breakdown of cartilage collagen, in which this cross link is mose abundant; in human bone collagen much of the relatively low pyridinium cross link content iș present as a deoxy analogue,$^{13}$ which shows little reactivity with the antibody ( $\mathrm{S} P$ Robins, unpublished results). Nevertheless, very large alterations in bone collagen turnover, as for example in Paget's disease, do give rise to increased pyridinoline excretion. ${ }^{15} 17^{g}$

There was considerable variation in cross link content of serial samples from individuals, and future studies will be designed to elucidate factors that contribute to the variability. Clearly this will require closer control of drug therapies as, in the present investigation, no systematic study of remedial treatment was undertaken. Both groups of arthritic patients were taking approximately comparable amounts of analgesic and anti-inflammatory drug therapy, neither of which are known to affect urinary pyridinoline levels. There was also little evidence from this study to suggest that the second line agents taken by the patients with rheumatoid arthritis were affecting urinary pyridinoline levels. The influence of diet on urinary pyridinoline is probably negligible,${ }^{17}$ especially in view of the very low contribution from dietary sources to the output of hydroxylysine derivatives ${ }^{6}$ that are precursors of the cross links. The possible effects of diurnal variations of pyridinoline with respect to creatinine have not yet been studied and more information on 
the effects of exercise on these parameters is clearly necessary.

Several reports have recorded increases with age in the pyridinoline content of certain tissues, ${ }^{1320}$ and moderate increases with age in urinary pyridinoline have been reported. ${ }^{17}$ Although the mean age of the control group in the major study was slightly lower than that of the RA or OA groups (Table 1), these age related differences would account for less than $10 \%$ of the observed increase in the pyridinoline/creatinine ratio.

Further work is required to determine whether subgroups of osteoarthritic patients (primary generalised osteoarthrosis and secondary osteoarthrosis) are associated with different levels of urinary pyridinoline, and serial studies are planned in patients with a variety of diseases to determine whether urinary pyridinoline alters in response to drug therapy. If this were the case, urinary pyridinoline would be a useful index of joint damage and its possible amelioration by drugs used for arthritis.

We acknowledge the advice and support we have received from $\mathrm{Dr}$ Noel Roberts at Roche Products Limited and we are indebted to Mr Andrew Cline of Roche Products Limited for the statistical analysis. CA and HB also acknowledge financial support from Roche Products Limited.

\section{References}

1 Kivirikko K I. Urinary excretion of hydroxyproline in health and disease. Int Rev Connect Tissue Res 1970; 5: 93-163.

2 Gielen J, Dequeker J. Drochmans A, Wildiers J, Merlevede M. Relevance of hydroxyproline excretion to bone metastasis in breast cancer. Br J Cancer 1976; 34: 279-85.

3 Kelleher P C. Urinary excretion of hydroxyproline, hydroxylysine and hydroxylysine glycosides by patients with Paget's disease of bone and carcinoma with metastases in bone. Clin Chim Acta 1979; 92: 373-9.
4 Bienkowski R S, Engels C J. Measurement of intracellular collagen degradation. Anal Biochem 1981; 116: 414-24.

5 Horlein D, Fictzek P P, Kuhn K. Pro-gin: the procollagen peptidase cleavage site in the $\alpha 1$ (I) chain of dermatosparactic calf skin procollagen. FEBS Lett 1978; 89: 279-82.

6 Segrest J P, Cunningham L W. Variations in human urinary O-hydroxylysyl glycoside levels and their relationship to collagen metabolism. J Clin Invest 1979; 49: 1497-509.

7 Pinnell S R, Fox R, Krane S M. Human collagens: differences in glycosylated hydroxylysines in skin and bone. Biochim Biophys Acta 1971; 229: 119-22.

8 Robins S P. Turnover and crosslinking of collagen. In: Weiss $\mathrm{J}$ B. Jayson M I V, eds. Collagen in health and disease. Edinburgh: Churchill Livingstone, 1982: 160-78.

9 Fujimoto D, Moriguchi T, Ishida T, Hayashi $H$. The structure of pyridinoline, a collagen crosslink. Biochem Biophys Res Commun 1978; 84: 52-7.

10 Eyre D R. Collagen: molecular diversity in the body's protein scaffold. Science 1980; 207: 1315-22.

11 Robins S P. Crosslinking of collagen: isolation, structural characterization and glycosylation of pyridinoline. Biochem $J$ 1983; 215: 167-73.

12 Robins S P, Duncan A. Crosslinking of collagen: location of pyridinoline in bovine articular cartilage at two sites of the molecule. Biochem J 1983; 215: 167-73.

13 Eyre D R, Koob T J, Van Ness K P. Quantitation of hydroxypyridinium crosslinks in collagen by high-performance liquid chromatography. Anal Biochem 1984; 137: 380-8.

14 Moriguchi T, Fujimoto D. Crosslink of collagen in hypertrophic scar. J Invest Dermatol 1979; 72: 143-5.

15 Robins S P. An enzyme-linked immunoassay for the collagen crosslink pyridinoline. Biochem J 1982; 207: 617-20.

16 Gunja-Smith Z, Boucek R J. Collagen crosslinking compounds in human urine. Biochem $J$ 1981; 197: 759-62.

17 Fujimoto D, Suzuki M, Uchiyama A, Miyamoto, S, Inoue T. Analysis of pyridinoline, a crosslinking compound of collagen fibres, in human urine. J Biochem 1983; 94: 1133-6.

18 Wilson B M, Makane P K. The covalent coupling of proteins to periodate-oxidized Sephadex: a new approach to immunoadsorbent preparation. J Immunol Methods 1976; 12: 171-81.

19 Ross G J S. Maximum likelihood program. Harpenden, Herts, UK: Rothamsted Experimental Station, 1980.

20 Fujimoto D. Aging and crosslinking in human aorta. Biochem Biophys Res Commun 1982; 109: 1264-9. 